\title{
Infección por citomegalovirus humano en neonatos de un hospital público de Mérida, Yucatán
}

\author{
Laura Conde-Ferráez, * Ana Lilia Ceh-Guerrero, José Reyes Canché-Pech, Guadalupe Ayora-Talavera y \\ María del Refugio González-Losa \\ Universidad Autónoma de Yucatán, Centro de Investigaciones Regionales "Dr. Hideyo Noguchi”, Unidad Biomédica, Yucatán, México
}

\section{Resumen}

Introducción: El citomegalovirus humano es reconocido como la causa más común de infección viral congénita, la cual puede darse como resultado de infección primaria, reinfección o reactivación en la mujer embarazada; además, puede ocasionar retraso en el desarrollo neuronal y pérdida auditiva sensoneural en el neonato. Objetivo: Identificar la infección por citomegalovirus humano en neonatos por PCR en tiempo real (PCR-TR) y cultivo celular. Método: Estudio observacional, longitudinal y retrospectivo con muestras de hisopado oral provenientes de 362 neonatos nacidos en un periodo de 10 meses en un hospital público de Mérida, Yucatán. Se realizó PCR-TR para la detección de citomegalovirus humano. Se obtuvo cultivo celular primario de fibroblastos a partir de tejido de prepucio humano para recuperar el virus. Se siguieron solo los casos positivos. Resultados: Se encontró 0.86 \% de infección por citomegalovirus humano por PCR-TR. No se recuperó el virus en cultivo. En las visitas de seguimiento, la salud sensorial y el neurodesarrollo fueron adecuados. Conclusión: La prevalencia de infección por citomegalovirus humano en neonatos fue similar a la de reportes mundiales y solo pudo evidenciarse por PCR. La infección asintomática detectada entre las 12 a 24 horas del nacimiento no tuvo consecuencias a largo plazo.

PALABRAS CLAVE: Citomegalovirus. Recién nacidos. Infección congénita. PCR en tiempo real. Cultivo celular.

\begin{abstract}
Introduction: Human cytomegalovirus (HCMV) is recognized as the most common cause of congenital viral infection, which can occur as a result of primary infection, reinfection or infection reactivation in the pregnant woman and be the cause of delay in neuronal development and sensorineural hearing loss in the neonate. Objective: To identify CMVH infection in newborns by real-time polymerase chain reaction (RT-PCR) and cell culture. Method: Observational, cross-sectional, retrospective study with oral swab samples from 362 neonates born within a 10-month period in a public hospital of Mérida, Yucatán. RT-PCR was carried out for the detection of HCMV. Fibroblast primary cell culture was obtained from human foreskin tissue to isolate the virus. Only positive cases were followed. Results: A prevalence of HCMV infection of $0.86 \%$ was found by RT$P C R$. No virus was isolated with cell culture. In the follow-up visits, sensory health and neurodevelopment were adequate. Conclusion: The prevalence of HCMV infection is similar to that of worldwide reports, and only was detected by RT-PCR. Asymptomatic infection detected 12-14 h after birth had no long-term health consequences.
\end{abstract}

KEY WORDS: Cytomegalovirus. Newborns. Congenital infection. Real time PCR. Cell culture.

Fecha de recepción: 19-09-2017

Fecha de aceptación: 24-01-2019

DOI: $10.24875 / G M M .19003736$
Gac Med Mex. 2019;155:336-342

Disponible en PubMed www.gacetamedicademexico.com 


\section{Introducción}

El citomegalovirus humano (CMVH) es un virus ampliamente distribuido en el mundo y es causa de varias enfermedades en los humanos, las cuales se relacionan con el estado de la respuesta inmune. $\mathrm{CMVH}$ es el miembro más representativo de la subfamilia Betaherpesvirinae (familia herpesviridae). Son virus envueltos de simetría icosaédrica y un genoma de ADN de doble cadena lineal con aproximadamente 120 a 250 kilopares de bases $(\mathrm{kpb}) .^{1-3}$

$\mathrm{CMVH}$ es un patógeno oportunista de amplia distribución mundial. ${ }^{3-5}$ Se ha reportado un aumento de su prevalencia en países en desarrollo, además, se incrementa con la edad y en poblaciones con malas condiciones socioeconómicas se adquiere a edades tempranas. ${ }^{3,6} \mathrm{La}$ infección por CMVH es la causa más importante de infección congénita en países desarrollados. ${ }^{7}$ La tasa de infección fetal es de 0.15 a $2 \%$ cuando hay primoinfección materna; en ese periodo, la tasa de transmisión vertical es de 20 a $45 \%$, de la cual 10 a $15 \%$ presentará infección clínica con $90 \%$ de secuelas. ${ }^{8-10}$ Países de América Latina como Chile, Ecuador y México muestran que al final de la niñez y la adolescencia, aproximadamente $90 \%$ de la población ya ha sido infectada con el virus y que casi todos los pacientes negativos para CMVH en esta edad sufre su primera infección durante la edad adulta temprana. ${ }^{8,9}$

Está documentado que 1 a $4 \%$ de las mujeres embarazadas padecerá la primoinfección a lo largo de su periodo gestacional, $40 \%$ transmitirá el $\mathrm{CMVH}$ al feto, la infección congénita afectará a $1 \%$ de los recién nacidos y la infección adquirida en el momento del parto tendrá lugar en 2 a $6 \%$ de los recién nacidos y habitualmente será asintomática. ${ }^{11-13} \mathrm{La}$ forma adquirida en el canal del parto ocasiona enfermedades respiratorias como bronquitis o neumonitis intersticial, manifestándose a partir de las tres semanas de vida. Entre 10 y $15 \%$ de niños con infecciones congénitas por $\mathrm{CMVH}$ asintomáticas en el periodo neonatal desarrollará problemas persistentes de gravedad variable, que pueden ser letales, entre ellos se han descrito malformaciones congénitas como comunicaciones intracardiacas, atresia de esófago o vías biliares, luxación congénita de cadera, cataratas, megacolon y pérdida auditiva neurosensorial. ${ }^{12,13}$ Por otro lado, en los recién nacidos prematuros de muy bajo peso, la infección posnatal por $\mathrm{CMVH}$ puede tener curso sintomático, en ocasiones graves. ${ }^{14}$
Los métodos recomendados para diagnosticar la infección por CMVH incluyen la detección de anticuerpos IgM y baja avidez de IgG, detección por PCR y cultivo viral a partir de muestras de orina o saliva obtenidas en las dos primeras semanas de vida del recién nacido..$^{15} \mathrm{El}$ cultivo celular se sigue considerando el estándar de oro para el diagnóstico de infección congénita en recién nacidos, ${ }^{15}$ si bien la detección en saliva ha demostrado ser una prueba muy poderosa y prometedora. ${ }^{16}$

El objetivo de este estudio fue determinar la prevalencia de la infección por $\mathrm{CMVH}$ en recién nacidos del Hospital O'Horan (Mérida, Yucatán, México) en muestras de saliva y describir los factores epidemiológicos presentes.

\section{Método}

Estudio observacional, transversal y retrospectivo, con una población de 362 muestras del repositorio del laboratorio de virología. Las muestras consistieron en hisopados orales conservados en congelación, tomados de neonatos de hasta 24 horas de nacidos, durante 2010 y 2011 en el Hospital General "Dr. Agustín O'Horan", Mérida, Yucatán, en un periodo de muestreo de 10 meses, como parte de un proyecto realizado con aprobación del Comité de Bioética del hospital (registro CIE-032-3-09).

Se incluyeron muestras de neonatos que contaban con expediente y cuyo ADN resultó positivo para el gen de $\beta$-globina (indicativo de calidad del ADN). Se excluyeron muestras sin expediente o con volumen insuficiente. Se eliminaron las que resultaron negativas para el gen de $\beta$-globina.

A partir del hisopado oral se extrajo el ADN total con el kit DNeasy Blood and Tissue ${ }^{\circledR}$ (Qiagen, Maryland, Estados Unidos). Para la determinación de la calidad del ADN obtenido se realizó la detección del gen $\beta$-globina por PCR en punto final según Saiki et $a .^{17}$

\section{PCR en tiempo real (PCR-TR)}

Para determinar la presencia de $\mathrm{CMVH}$ en las muestras se realizó PCR en tiempo real (PCR-TR). La reacción se realizó a partir de aproximadamente $20 \mathrm{ng} / \mathrm{\mu L}$ de ADN, ajustando el protocolo descrito por Griscelli et al.:18

- A la mezcla de reacción TaqMan Universal PCR Master Mixture $^{\circledast}$ (Thermo Fisher Scientific, Foster City, CA, Estados Unidos) se adicionaron los 
oligonucleótidos CMVF-UL83 5'- y CMVR-UL83 a una concentración de $0.4 \mu \mathrm{M}$; y la sonda TaqMan ${ }^{\circledR}$ marcada con FAM, a una concentración de $0.1 \mu \mathrm{M}$. Todos los ensayos se realizaron en equipo 7500 Fast Real-Time PCR System. La valoración del producto de amplificación se llevó a cabo con base en el número de ciclos de amplificación asociados con la fluorescencia emitida por la sonda $\operatorname{TaqMan}^{\circledR}(\mathrm{Ct})$. Como control positivo, se utilizó una clona preparada en nuestro laboratorio, de un vector plasmídico que contiene como inserto un fragmento del gen de UL83 de CMVH AD169, la cual fue verificada previamente por secuenciación Sanger (datos no presentados). Como control negativo se usó una mezcla libre de ácidos nucleicos.

\section{Cultivo celular}

Se obtuvo un cultivo primario de fibroblastos humanos (HFF, human foreskin fibroblasts), a partir de tejidos de prepucio de neonatos circuncidados electivamente en una clínica privada, donados por sus padres voluntariamente. Los tejidos se cortaron en fragmentos pequeños. Las células se obtuvieron por incubación del tejido con tripsina a $0.05 \%\left(\right.$ Gibco $^{\circledR}$, Thermo Fisher Scientific) y PBS 1:6. Las células disgregadas se filtraron e incubaron en medio de Eagle modificado por Dulbecco (DMEM), suplementado con suero fetal bovino a $10 \%$, L-glutamina a $1 \%$, gentamicina a $200 \mu \mathrm{g} / \mathrm{mL}$, estreptomicina, penicilina y anfotericina B a $2.5 \mu \mathrm{g} / \mathrm{mL}$. Se cultivaron a $37^{\circ} \mathrm{C}$ y a $5 \%$ de $\mathrm{CO}_{2}$. Cuando el cultivo llegó a confluencia entre las cuatro y seis semanas, se realizó el primer pase y se mantuvo hasta el pase número 26.

\section{Infección de las células de cultivo primario de fibroblastos}

Una vez que el cultivo de fibroblastos alcanzó los pases 15 a 18, se comprobó la susceptibilidad de los HFF para ser infectados con un virus de referencia. Dado que no se contaba con la cepa de referencia CMVH-AD169, se utilizaron otros virus de la misma familia herpesviridae, virus del herpes simple tipos 1 y 2 (VHS1 y VHS2, cepas de referencia Mclntyre y G). El efecto citopático en las células se tomó como indicativo de infección. Para realizar las infecciones del cultivo celular a partir de muestras positivas a $\mathrm{CMVH}$, se pasaron por un filtro Swinnex Filter Holder $^{\circledR}$ de
Tabla 1. Distribución del número de semanas de gestación en la población de estudio

\begin{tabular}{|l|c|c|}
\hline Semanas de gestación & Frecuencia & $\%$ \\
\hline $30-34$ & 14 & 3.88 \\
\hline $35-39$ & 248 & 68.50 \\
\hline $40-43$ & 100 & 27.62 \\
\hline Total & 362 & 100.00 \\
\hline
\end{tabular}

$13 \mathrm{~mm}$ (Merck Millipore, Concord Road Massachusetts, Estados Unidos) y se centrifugaron a $20000 \mathrm{rpm}$ a $4{ }^{\circ} \mathrm{C}$. El sobrenadante se resuspendió en $200 \mu \mathrm{L}$ de DMEM con suero fetal bovino a $2 \%$, para inocular las células HFF en estado de confluencia. Se evaluó el efecto citopático desde los primeros cuatro días de la infección hasta los 21 días posinfección.

\section{Seguimiento de casos positivos}

Solamente se dio seguimiento a los casos que resultaron positivos a $\mathrm{CMVH}$ en el domicilio reportado en el expediente. Los niños fueron valorados por estudiantes de la licenciatura en rehabilitación de acuerdo con la Guía de Evaluación para el Desarrollo Motor y la Actividad Física para Pacientes Pediátricos, basada en parámetros generales de la Organización Panamericana de la Salud y proporcionada por la Coordinación de la Licenciatura en Rehabilitación de la Universidad Autónoma de Yucatán. Asimismo, se entrevistó a las madres respecto a la edad de inicio de ciertos indicadores de motricidad (como marcha, gateo, capacidad de tomar objetos, de alimentarse y de garabateo); lenguaje (inicio del balbuceo, palabras que conoce y capacidad de seguir instrucciones simples) e indicadores generales de salud (si ha estado hospitalizado, presentado convulsiones, etcétera).

\section{Resultados}

\section{Características generales de la población de estudio}

Se seleccionaron 362 muestras para el estudio, con sus respectivos expedientes. Entre las características de los nacimientos se registró un promedio de 38.33 semanas de gestación (Tabla 1), 201 cesáreas $(55.50 \%)$ y $161(44.5 \%)$ partos por vía vaginal, de los cuales en 45 (12.4\%) ocurrió ruptura prematura de membranas. 
Tabla 2. Características de los neonatos positivos

\begin{tabular}{|l|l|c|c|c|c|c|l|l|l|}
\hline $\begin{array}{l}\text { Número de } \\
\text { muestra }\end{array}$ & Sexo & Peso $(\mathrm{kg})$ & Talla $(\mathrm{cm})$ & $\begin{array}{c}\text { Perímetro } \\
\text { cefálico }(\mathrm{cm})\end{array}$ & Apgar & $\begin{array}{l}\text { Semanas de } \\
\text { gestación }\end{array}$ & $\begin{array}{l}\text { Tipo de } \\
\text { parto }\end{array}$ & $\begin{array}{l}\text { Presentación } \\
\text { cefálica }\end{array}$ \\
\hline 052 & Masculino & 2.96 & 49 & 33 & $8 / 9$ & 39 & Cesárea & Sí \\
\hline $236^{*}$ & Femenino & 2.06 & 45 & 32 & $8 / 9$ & 36 & Vaginal & Sí \\
\hline 263 & Masculino & 2.79 & 39 & 33 & $9 / 9$ & 39 & Vaginal & Sí
\end{tabular}

*Embarazo gemelar.

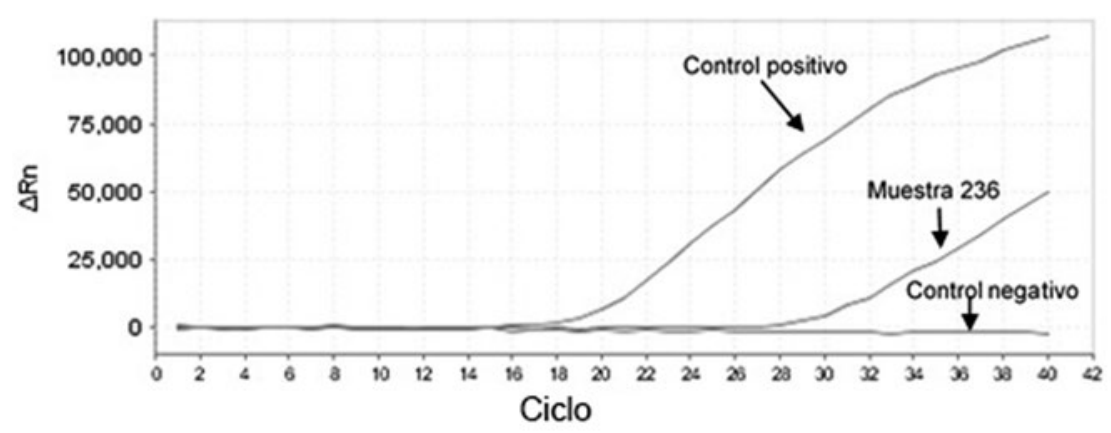

Figura 1. Resultado representativo del ensayo de PCR-TR para CMVH. Amplificación de una muestra clínica positiva y controles positivo y negativo. Las gráficas presentan las curvas de amplificación en unidades de fluorescencia, expresadas como la diferencia en la intensidad normalizada del flouróforo reportada menos la florescencia base $(\Delta R n)$ a lo largo de los ciclos de amplificación (eje horizontal).
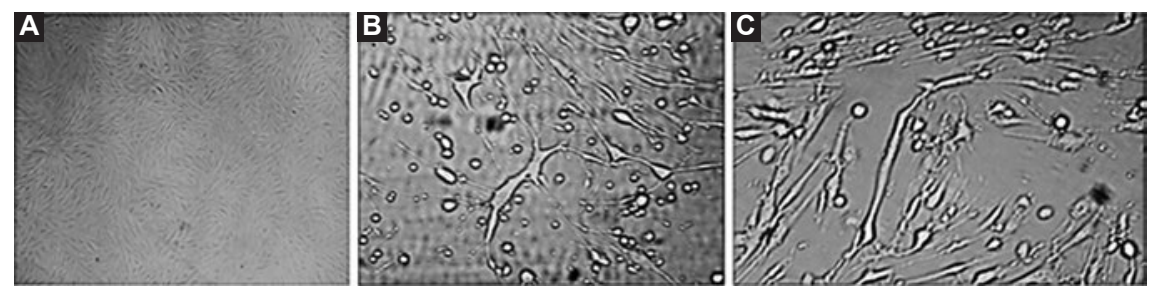

Figura 2. Ensayos de cultivo celular. A) Monocapa de cultivo primario de fibroblastos de prepucio humano (HFF). B) Efecto citopático en HFF infectados por herpes virus simple tipos 10 2. C) Células en el pase 7. Imágenes con luz blanca de microscopio óptico invertido a 10x (A) y 40x (B y C).

Respecto a las madres de los neonatos, $22.9 \%$ tenía entre 16 y 18 años de edad y $77 \%$ de 19 años en adelante; $31.8 \%$ contaba con estudios hasta nivel secundaria, $11.3 \%$ hasta preparatoria y $1.7 \%$ estudios de licenciatura. Adicionalmente, $96.1 \%$ no presentó antecedentes de enfermedades de transmisión sexual.

\section{Detección del CMVH por PCR-TR en los recién nacidos}

De las 362 muestras para realizar la PCR-TR, se logró obtener resultados de $95.30 \%$ (345/362). Las muestras procedían de 168 (46.40\%) neonatos del sexo femenino y 194 (53.60\%) del masculino, con peso promedio al nacer de $2.99 \mathrm{~kg}$ y talla promedio de $49.56 \mathrm{~cm}$. Se encontraron malformaciones congénitas en cinco de los 345 neonatos: dedo supernumerario del pie o labio y paladar hendidos. Ninguno presentó datos clínicos sugerentes de infección aguda por $\mathrm{CMVH}$.

La PCR-TR arrojó un resultado de tres muestras positivas a CMVH y 342 negativas, lo que correspondió a una frecuencia de $0.86 \%$ en la población de estudio. Las características de los resultados positivos se presentan en la Tabla 2.

Los valores de Ct para las muestras 52, 236 y 263 fueron respectivamente de 35,33 y 29; se tomó como criterio para considerar una muestra como positiva para infección por CMVH valores entre 1 y 39 (Figura 1).

\section{Establecimiento del cultivo celular}

Se obtuvo el cultivo primario de fibroblastos a partir de tejidos de prepucio humano, hasta obtener una monocapa de un solo tipo celular libre de queratinocitos. Los fibroblastos fueron cultivados hasta el pase número 26; en la Figura $2 \mathrm{~A}$ se presenta una monocapa confluente 
del cultivo primario obtenido. Los fibroblastos fueron susceptibles a la infección por VHS1 y VHS2 ya que se observó el efecto citopático como consecuencia de la infección viral desde las 24 a 48 horas y 48 a 96 horas posinfección, respectivamente (Figuras $2 \mathrm{~B}$ y $2 \mathrm{C}$ ). Sin embargo, al inocular la monocapa con muestras positivas a $\mathrm{CMVH}$, no fue posible recuperar virus y el cultivo presentó senescencia antes de presentar algún efecto citopático identificable por microscopía.

\section{Seguimiento de los positivos}

Los casos positivos fueron visitados en su domicilio entre 18 y 20 meses después de su nacimiento. Se localizó el domicilio del caso 236 en el municipio de Halachó (zona urbana al poniente del Yucatán) y el 263 en Chacsinkin (zona rural maya al sur del estado); el 52 no pudo ser ubicado en Playa del Carmen (zona urbana de Quintana Roo), aparentemente por cambio de domicilio. En el caso 236, que fue embarazo gemelar, se valoró a ambos infantes, aunque solo uno había resultado positivo en la detección a $\mathrm{CMVH}$. Todos presentaron talla, peso y neurodesarrollo de acuerdo con su edad, sin hipoacusia ni disminución de la visión. En la entrevista a las madres, estas refirieron condiciones motoras y de lenguaje adecuadas en edades anteriores. Por lo tanto, la infección al momento del nacimiento que tuvo un curso asintomático e inaparente no afectó a largo plazo las áreas valoradas.

\section{Discusión}

En este estudio pudimos detectar ADN de CMVH en la saliva de tres neonatos del hospital en estudio, que correspondió a $0.86 \%$ de prevalencia.

La infección por citomegalovirus es altamente prevalente a nivel mundial.16,19 La transmisión vertical ocurre en $40 \%$ de los casos de madres infectadas ${ }^{20}$ y puede ser por vía transplacentaria, al paso del neonato por el canal del parto o después del nacimiento por contacto con secreciones del tracto genital materno, por alimentación con leche materna 0 a través de líquidos biológicos. ${ }^{21}$ Ya que las muestras de nuestro proyecto se tomaron entre las 12 y 24 horas de nacimiento, se sugiere que los niños pudieron ser infectados durante la gestación; la infección congénita es indudable en el caso del infante nacido por cesárea, sin embargo, la contaminación durante el paso del canal de parto no puede excluirse en los dos que nacieron vía vaginal.
En el caso 236 se trató de un embarazo gemelar, del que solamente uno de los productos resultó positivo; aún no se conoce con detalle los mecanismos de transmisión que pueden estar participando en este tipo de casos.

En México, la infección por CMVH es la primera causa de hipoacusia y sordera sensorioneural en los niños, además de ser causante de parálisis cerebral y trastornos cognitivos. ${ }^{22}$ En las valoraciones de seguimiento de los niños positivos no se identificaron consecuencias a largo plazo de la infección detectada al nacimiento.

El valor de prevalencia encontrado está en concordancia con los resultados de estudios en otras poblaciones en el mundo, incluso es ligeramente más alto: en una investigación realizada con neonatos de siete hospitales de Estados Unidos entre 2008 y 2012, la evaluación de CMVH por PCR-TR mostró una prevalencia de neonatos infectados de $0.36 \%$ (266 muestras positivas de 72 239). ${ }^{23}$ Existen pocos reportes que analicen al CMVH en México: en un estudio de PCR punto final anidado a partir de muestras de sangre en papel filtro del tamizaje neonatal se obtuvo $0.68 \%$ de prevalencia de infección congénita por CMVH en el estado de San Luis Potosí. ' Los mismos autores mencionan que el tipo de muestra utilizado puede tener baja sensibilidad diagnóstica, por lo que consideran que es una subestimación de la prevalencia. En nuestro caso obtuvimos una mayor frecuencia $(0.86 \%)$ de positividad en las muestras de hisopados orales y con un método de PCR en tiempo real con sondas fluorescentes.

Adicionalmente, realizamos el cultivo celular con intención de corroborar el resultado obtenido por PCR-TR. Dado que en Yucatán no se cuenta con este sistema de diagnóstico, nos propusimos estandarizar la técnica. Se ha reportado el uso de líneas celulares de fibroblastos para llevar cabo la infección con $\mathrm{CMVH},{ }^{24,25}$ sin embargo, es necesario comprar las líneas celulares y adecuar un sistema de criopreservación para mantenerlas.

Para evitar los requerimientos anteriores, en este trabajo obtuvimos fibroblastos por cultivo primario a partir de muestras de tejidos de circuncisión electiva de neonatos, a pesar de lo cual no logramos observar la infección de $\mathrm{CMVH}$ a partir de muestras positivas por PCR-TR, probablemente debido a causas atribuibles a las muestras, como haber trabajado con muestras de un repositorio, ya que el proceso de congelación y descongelación puede afectar la infectividad. Adicionalmente, la baja carga viral en las 
muestras puede limitar la recuperación por cultivo, lo cual se evidenció en los valores altos de $\mathrm{Ct}$ obtenidos por PCR-TR.

El Ct (o ciclo umbral) indica el ciclo de la PCR en el cual la curva de amplificación cruza la línea umbral y alcanza la amplificación exponencial. Este valor se relaciona directamente con el número de copias del $A D N$, de manera que un $\mathrm{Ct}$ menor corresponde a una carga viral más alta que un $\mathrm{Ct}$ mayor. Aunque no se trató de una PCR cuantitativa (requiere el uso de una curva estándar, lo que encarece el ensayo), observamos Ct elevados, lo cual indica baja concentración viral. En nuestra experiencia, un Ct de 34 representa una carga viral de aproximadamente 1500 copias $/ \mu \mathrm{L}$ (datos no publicados). Como referencia, las guías del Instituto Mexicano del Seguro Social ${ }^{26}$ indican como corte $>10^{5]}$ copias $/ \mathrm{mL}$ de líquido amniótico como predictor de infección sintomática, sin embargo, este valor puede no ser comparable y no hay puntos de corte para saliva.

La PCR-TR es una herramienta valiosa en epidemiología y en la clínica, además, es una ventaja que se utilice una muestra no invasiva como el hisopado oral, el cual resulta más rápido y económico. ${ }^{23}$

Dado que la infección por $\mathrm{CMVH}$ en recién nacidos transmitida verticalmente es un problema subdiagnosticado debido a la amplia gama de sintomatología que pueden presentar los pacientes, ${ }^{27}$ es de gran importancia realizar un diagnóstico temprano y preciso para tratar al recién nacido y reducir las complicaciones a largo plazo.

EI PCR en tiempo real ofrece beneficios en cuanto a sensibilidad y simplicidad ${ }^{28-30}$ por lo que es posible detectar muestras positivas con carga viral baja. ${ }^{26}$

Una limitante de este trabajo fue que no se dispuso de datos serológicos de las madres de los neonatos estudiados. Sin embargo, podemos suponer que un elevado porcentaje de las madres eran seropositivas, basándonos en un estudio en embarazadas del mismo hospital que indicó $97 \%$ de seroprevalencia y baja incidencia de primoinfección durante la gestación (1.6\%), lo que indica que el riesgo de infección congénita es también bajo. ${ }^{31}$ Lo anterior coincide con las observaciones. Sería importante estudiar la concordancia entre los datos serológicos de la madre y la excreción viral en el neonato al momento del nacimiento.

\section{Conclusión}

Se determinó la prevalencia de la infección por $\mathrm{CMVH}$ en recién nacidos del Hospital O’Horan en muestras de saliva utilizando PCR-TR, prueba que demostró las ventajas de los métodos moleculares en cuanto a mayor rapidez, sensibilidad y economía respecto al cultivo celular. Las infecciones asintomáticas detectadas 12 a 24 horas del nacimiento no tuvieron repercusiones a largo plazo. Los resultados de la investigación generaron evidencia de la utilidad de la PCR-TR como método de detección del $\mathrm{CMVH}$, para contribuir al conocimiento de la epidemiología de la infección por este patógeno.

\section{Agradecimientos}

A Perla Edith Padilla Ríos, por su apoyo en la obtención de los tejidos de prepucios; al doctor José Arellano Galindo, del Hospital Infantil "Federico Gómez", por proporcionar ADN de control de CMVH. A la doctora Blanca Lilia Barrón Romero, de la Escuela Nacional de Ciencias Biológicas-IPN, por donar las cepas de referencia de VHS. A los estudiantes de la Licenciatura en Rehabilitación de la Universidad Autónoma de Yucatán, por su apoyo en la valoración de los pacientes positivos. Este estudio se realizó con recursos de los financiamientos Promep103-5/08/2008 y Conacyt-Salud-2009-01-113380.

\section{Bibliografía}

1. Rawlinson WD, Hamilton ST, van Zuylen WJ. Update on treatment of cytomegalovirus infection in pregnancy and of the newborn with congenital cytomegalovirus. Curr Opin Infect Dis. 2016;29:615-624.

2. Bascones-Martínez A, Pousa-Castro X. Herpesvirus. Av Odontoestomatol. 2011;27:11-24

3. Manicklal S, Emery VC, Lazzarotto T, Boppana SB, Gupta RK. The "silent" global burden of congenital cytomegalovirus. Clin Microbiol Rev. 2013;26:86-102

4. Weller TH. Cytomegalovirus: a historical perspective. Herpes. 2000;7: 66-69.

5. Staras SA, Dollard SC, Radford KW, Flanders D, Pass R, Cannon MJ. Seroprevalence of cytomegalovirus infection in the United States, 19881994. Clin Infect Dis. 2006;43:1143-1151.

6. Noyola DE, Matienzo-Serment L, Rodríguez-Vidal SO, Ochoa-Pérez UR, Piña-Granja JM, García-Sepúlveda CA. Infección congénita por citomegalovirus en recién nacidos del estado de San Luis Potosí, México. Salud Publica Mex. 2011:53:513-515.

7. Kadambari S, Williams EJ, Luck S, Griffiths D, Sharland M. Evidence based management guidelines for the detection and treatment of congenital CMV. Early Hum Dev. 2011;87:723-728.

8. Dolan A, Cunningham C, Hector RD, Hassan WA, Lee L, Addison C, et al. Genetic content of wild-type human cytomegalovirus. J Gen Virol. 2004;85:1301-1302.

9. Noyola DE, Jiménez-Capdeville ME, Demmler-Harrison GJ. Central nervous system disorders in infants with congenital cytomegalovirus infection. Neurol Res. 2010;32:278-279.

10. Suárez AM, Rovira AS, López MC, Esteban DI. Citomegalovirus congénito: revisión de tres casos con diferentes formas de presentación. Bol Pediatr Arag Rioj Sor. 2007;37:23.

11. Diestéfano A, González A, Pardón F, Sarubi M, Canero C. Diagnóstico de la infección congénita por citomegalovirus en muestras de sangre seca de recién nacidos en la Tarjeta Guthrie. Una técnica promisoria. Arc Argent Pediatr. 2008;106:132-137.

12. Juárez $A A$, Islas $D L$, Durán $P M$, Buitrón GR. Infección congénita letal por citomegalovirus. Rev Mex Pediatr. 2009;76:170-171.

13. Barbi M, Binda S, Caroppo S, Primache V. Neonatal screening for congenital cytomegalovirus infection and hearing loss. J Clin Virol. 2006; 35:206-209. 
14. Alarcón-Allen A, Baquero-Artigao F, Grupo de estudio de la infección por citomegalovirus de la Sociedad Española de Infectología Pediátrica. Review and guidelines on the prevention diagnosis and treatment of post-natal cytomegalovirus infection. An Pediatr (Barc). 2011;74:52.e152.e13.

15. Ross SA, Novak Z, Pati S, Boppana SB. Diagnosis of cytomegalovirus infections. Infect Disord Drug Targets. 2011;11:466-474.

16. Boppana SB, Ross SA, Shimamura M, Palmer AL, Ahmed A, Michaels MG, et al. Saliva polymerase-chain-reaction assay for cytomegalovirus screening in newborns. N Engl J Med. 2011;364:2111-2118.

17. Saiki RK, Bugawan TL, Horn GT, Mullis KB, Erlich HA. Analysis of 315 enzymatically amplified beta-globin and HLA-DQ alpha DNA with allele-specific 316 oligonucleotide probes. Nature. 1986;324:163-166.

18. Griscelli F, Barrois M, Chauvin S, Lastere S, Bellet D, Bourhis J. Quantification of human cytomegalovirus DNA in bone marrow transplant recipients by real-time PCR. J Clin Microbiol. 2001;39:4362-4363.

19. Suárez A, Monsalve-Castillo F, Romero T, Costa-León L, Mindiola R, et al. Prevalencia de la infección por citomegalovirus en mujeres fértiles de comunidades indígenas Yulapa, estado de Zulia, Venezuela. Kasmera. 2009;37:168-178.

20. Rodríguez M, Juárez-De León G, Astudillo J, Hasbún J, Parra M. Infección congénita por citomegalovirus: nuevos aspectos terapéuticos. Rev Chil Obstet Ginecol. 2008;73:S717-752.

21. Salvia M, Álvarez E, Bosch J, Goncé A. Infecciones congénitas. España: Hospital Clínic; 2008

22. Pinillos-Pisón R, Llorente-Cereza MT, López-Pisón J, Pérez-Delgado R, Lafuente-Hidalgo M, Martínez-Sapiñá JL, et al. Infección congénita por citomegalovirus. Revisión de nuestra experiencia diagnóstica de 18 años. Rev Neurol. 2009;48:349-353.
23. Pinninti SG, Ross SA, Shimamura M, Novak Z, Palmer AL, Ahmed A, et al. Comparison of saliva PCR assay versus rapid culture for detection of congenital cytomegalovirus infection. Pediatr Infect Dis J. 2015; 34:536-537.

24. Leland DS, Ginocchio CC. Role of Cell culture for virus detection in the age of technology. Clin Microbiol Rev. 2007;20:49-78.

25. Hematian A, Sadeghifard N, Mohebi R, Taherikalani M, Nasrolahi A Amraei $\mathrm{M}$, et al. Traditional and modern cell culture in virus diagnosis. Osong Public Health Res Perspect. 2016;7:77-82.

26. Secretaría de Salud. Guía de práctica clínica. Prevención, diagnóstico y tratamiento de la infección por citomegalovirus en la edad pediátrica. México: Secretaría de Salud; 2012.

27. Pang X, Chui L, Featon J, LeBlanc B, Preiksaitis JK. Comparison of Lightcycler-based PCR, COBAS amplicor CMV Monitor, and pp65 antigenemia assay for quantitative measurement of cytomegalovirus viral load in peripheral blood specimens from patients after solid organ transplantation. J Clin Microbiol. 2003;41:3167-3174.

28. Gault E, Michel Y, Dehée A, Belabani C, Nicolas J, Garbarg-Chenon A. Quantification of human cytomegalovirus DNA by real-time PCR. J Clin Microbiol. 2001;37:772-775.

29. Jasso L. Infecciones congénitas de baja frecuencia en los neonatos. Algunos aspectos relevantes. Bol Med Hosp Infant Mex. 2011;68:7-20.

30. Varani S, Landini, MP. Cytomegalovirus-induced immunopathology and its clinical consequences. Herpesviridae. 2011;2:6-20.

31. Polanco-Marín G, Puerto F, Puerto-Solís M, González-Losa M, Albertos-Alpuche N, Manuel A. Prevalencia e incidencia de infección por citomegalovirus en mujeres embarazadas del estado de Yucatán, México. Rev Biomed. 1996;7:127-131. 